Article

\title{
Sodium Thiosulfate in the Pregnant Dahl Salt-Sensitive Rat, a Model of Preeclampsia
}

\author{
Fieke Terstappen ${ }^{1,2, t, * \mathbb{C}}$, Sinéad M. Clarke ${ }^{1,+}{ }^{\dagger}$ Jaap A. Joles ${ }^{3} \mathbb{1}$, Courtney A Ross ${ }^{4}$, \\ Michael R. Garrett ${ }^{4}$, Magdalena Minnion ${ }^{5,6}$, Martin Feelisch ${ }^{5,6}$, Harry van Goor ${ }^{7}$ (1), \\ Jennifer M. Sasser ${ }^{4}\left(\right.$ and A. Titia Lely ${ }^{1}$ \\ 1 Department of Obstetrics, Wilhelmina Children's Hospital, University Medical Center Utrecht, \\ 3508GA Utrecht, The Netherlands; sineadclarke92@gmail.com (S.M.C.); a.t.lely@umcutrecht.nl (A.T.L.) \\ 2 Department of Developmental Origins of Disease (DDOD), Wilhelmina Children's Hospital, \\ University Medical Center Utrecht, 3508GA Utrecht, The Netherlands \\ 3 Department of Nephrology and Hypertension, University Medical Center Utrecht, 3508GA Utrecht, \\ The Netherlands; J.A.Joles@umcutrecht.nl \\ 4 Department of Pharmacology and Toxicology, University of Mississippi Medical Center, Jackson, \\ MS 39216-4505, USA; cross3@umc.edu (C.A.R.); MRGarrett@umc.edu (M.R.G.); jsasser@umc.edu (J.M.S.) \\ 5 Clinical and Experimental Sciences, Faculty of Medicine, University of Southampton, \\ Southampton SO16 6YD, UK; M.Minnion@soton.ac.uk (M.M.); M.Feelisch@soton.ac.uk (M.F.) \\ 6 NIHR Southampton Biomedical Research Center, Southampton General Hospital, \\ Southampton SO16 6YD, UK \\ 7 Department of Pathology and Medical Biology, University Medical Center Groningen, University of \\ Groningen, 9713GZ Groningen, The Netherlands; h.van.goor@umcg.nl \\ * Correspondence: F.Terstappen@umcutrecht.nl; Tel.: +31-88-757-7251 \\ + These authors contributed equally to this work.
}

Received: 29 January 2020; Accepted: 12 February 2020; Published: 14 February 2020

\begin{abstract}
Aberrant production of hydrogen sulfide $\left(\mathrm{H}_{2} \mathrm{~S}\right)$ has been linked to preeclampsia. We hypothesized that sodium thiosulfate (STS), a $\mathrm{H}_{2} \mathrm{~S}$ donor, reduces hypertension and proteinuria, and diminishes fetal growth restriction in the Dahl salt-sensitive (S) rat, a spontaneous model of superimposed preeclampsia. In addition to a control group $(n=13)$, two groups received STS via drinking water at a dose of $2 \mathrm{~g}(\mathrm{n}=9)$ or $3 \mathrm{~g}$ per $\mathrm{kg}$ body weight per day $(\mathrm{n}=8)$ from gestational day (GD) 10 to 20 . Uterine artery resistance index was measured (GD18), urinary protein excretion rate was determined (GD19), and blood pressure and fetal outcomes were evaluated (GD20). At $2 \mathrm{~g}$, STS had no effect on preeclamptic symptoms or fetal outcome. At $3 \mathrm{~g}$, STS reduced maternal hypertension (121.8 \pm 3.0 vs. $136.3 \pm 2.9)$, but increased proteinuria ( $89 \pm 15$ vs. $56 \pm 5 \mathrm{mg} / 24 \mathrm{~h}$ ), and relative kidney weight ( $0.86 \pm 0.04$ vs. $0.73 \pm 0.02 \%)$. Fetal/placental weight ratio was reduced $(3.83 \pm 0.07$ vs. $4.31 \pm 0.08)$ without affecting litter size. No differences in uterine artery flow or renal histological damage were noted across treatment groups. While these data suggest a promising antihypertensive effect that could imply prolongation of preeclamptic pregnancies, the unfavorable effects on proteinuria, kidney weight, and fetal/placental weight ratio implies that clinical implementation of STS is contra-indicated until safety for mother and child can be verified.
\end{abstract}

Keywords: blood pressure; cardiovascular; Dahl salt-sensitive rats; fetal growth restriction; hydrogen sulfide; preeclampsia; sodium thiosulfate; therapeutics 


\section{Introduction}

Preeclampsia (PE) complicates $3 \%$ to $5 \%$ of all pregnancies and is a leading cause of maternal and perinatal mortality [1,2]. PE presents after 20 weeks of gestation and is characterized by hypertension accompanied by maternal organ disturbances (including proteinuria), as well as fetal growth restriction (FGR) [3]. Iatrogenic premature delivery is often required to preserve maternal health and to prevent stillbirths. Because PE is directly life-threatening to mother and child and leaves an unmitigated long-term cardiovascular risk for both in its wake, there is a considerable unmet need for treatment options [2-6].

The complex pathogenesis of PE is not fully understood. PE is considered a sequel to an undesirable interaction between placental and maternal constitutional factors $[2,5]$. The hypoxic placenta secretes proinflammatory cytokines (tumor necrosis factor alpha [TNF- $\alpha]$ and interleukin-6) and anti-angiogenic factors (soluble Fms-like tyrosine kinase 1 [sFlt1] and soluble endoglin [sENG]) [2,7]. The resulting systemic endothelial dysfunction eventually leads to the cardinal symptoms of PE [2,5].

Dysregulation of the hydrogen sulfide $\left(\mathrm{H}_{2} \mathrm{~S}\right)$ pathway has been suggested to contribute to the underlying mechanisms of PE and FGR. $\mathrm{H}_{2} \mathrm{~S}$ contains pro-angiogenic, anti-inflammatory, vasodilatory, and antioxidant properties, and thus is important in vascular adaptation [8-10]. This gasotransmitter is endogenously produced in the placenta from L-cysteine by enzymes including cystathionine $\beta$-synthase (CBS) and cystathionine $\gamma$-lyase (CSE) [11]. Several studies have shown that placental production of $\mathrm{H}_{2} \mathrm{~S}$, expression of $\mathrm{CBS}$ and CSE, and plasma $\mathrm{H}_{2} \mathrm{~S}$ concentrations are all reduced in pregnancies complicated by PE and FGR $[8,10]$. These aberrant $\mathrm{H}_{2} \mathrm{~S}$ levels have been linked to the anti-angiogenic environment and endothelial dysfunction associated with PE [12,13].

The potential of $\mathrm{H}_{2} \mathrm{~S}$ as a mechanism-based therapy for PE has been tested with several $\mathrm{H}_{2} \mathrm{~S}$ donors [11,14]. In rat models of $\mathrm{PE}$, administration of sodium hydrosulfide (NaHS) and GYY4137 (synthetic $\mathrm{H}_{2} \mathrm{~S}$ donor) reduced hypertension and circulating sFlt-1 levels, and increased fetal weight $[8,15]$. More recently, sodium thiosulfate (STS, $\mathrm{Na}_{2} \mathrm{~S}_{2} \mathrm{O}_{3}$ ) caught clinical interest as this $\mathrm{H}_{2} \mathrm{~S}$ donor, in contrast to other $\mathrm{H}_{2} \mathrm{~S}$ donors, is already approved for human use (e.g., in calciphylaxis, cyanide poisoning or protection against cisplatin toxicity) and can conveniently be administered orally $[9,16]$. Thiosulfate produces $\mathrm{H}_{2} \mathrm{~S}$ through enzymatic and non-enzymatic pathways in a glutathione-dependent manner. $\mathrm{H}_{2} \mathrm{~S}$, glutathione disulfide, and labeled sulfite are generated when mitochondria are incubated with glutathione, STS, and oxygen [17]. Indeed, we found that STS ameliorated hypertension and proteinuria in an angiotensin-II model of cardiac disease in male rats [16]. However, STS has not yet been tested in an animal model of PE.

Dahl salt-sensitive (S) rats are a spontaneous model of hypertension and kidney disease $[18,19]$. Pregnant Dahl S rats develop features of PE, including exacerbation of hypertension and proteinuria, FGR, increased placental hypoxia, and increased plasma levels of sFlt-1 and TNF- $\alpha$ [20]. Pregnant Dahl $S$ rats showed glomerulomegaly during late pregnancy as compared with virgin Dahl $S$ rats, a trend not observed in virgin versus pregnant non-Dahl $S$ rats [20]. As in preeclamptic women, the pregnant Dahl S rat exhibits sustained high uterine artery resistance (UARI) with characteristic notching in Doppler waveforms [20].

In this study, we test whether oral administration of STS in pregnant Dahl S rats attenuates the maternal preeclamptic phenotype (high blood pressure, proteinuria, and high UARI) and improves fetal outcomes (fetal and placental weight, litter size).

\section{Materials and Methods}

\subsection{Animals}

A total of 40 nulliparous Dahl S female rats (12 to 14 weeks, $232 \pm 11 \mathrm{~g}$ ) were acquired from Dr. Garrett's colony at the University of Mississippi (MS) Medical Center (UMMC), Jackson, MS. In order to achieve pregnancy, one to two female rats were housed with one Dahl S male rat per cage under controlled conditions $\left(12 \mathrm{~h}\right.$ light/dark cycle, $\left.23^{\circ} \mathrm{C}\right)$. Presence of sperm on vaginal smears 
indicated gestational day (GD) one. The rats had free access to water and normal chow (TD7034, $0.3 \% \mathrm{NaCl}$, Harlan Teklad, Madison, WI, USA). Conventional (type 3) cages were provided with sani-chip bedding (7090 Teklad Laboratory Grade) and enriched with a paper straw as nesting material. Ten Dahl S rats were excluded from analysis due to failure to achieve pregnancy, failure to accurately determine GD1, or death resulting from post-operative complications. As a result, 30 rats were included in the final analysis. The experiments were carried out in accordance with the National Institutes of Health Guide for the Care and Use of Laboratory Animals and approved by the UMMC Institutional Animal Care and Use Committee (protocol 1344A "New animal models to investigate hypertensive complications of pregnancy", approved on 24 September 2015, amended on 6 November 2017, and renewed as protocol 1344B on 1 June 2018), and reported according to ARRIVE guidelines.

\subsection{Study Protocol}

\subsubsection{Sodium Thiosulfate Treatment}

Dahl S rats were stratified into control $(n=13)$ and treatment groups. Littermates were assigned to different treatment groups, and we checked that average baseline urinary protein excretion rates (one week prior to pregnancy) were similar among the three groups (a cardinal feature of PE) to ensure indirectly that all groups had equal degrees of pre-existent renal injury. STS pentahydrate (EMSURE, Inc, Sigma) was administered at two different doses, $2 \mathrm{~g}$ per $\mathrm{kg}$ body weight per day $(\mathrm{n}=9)$ and $3 \mathrm{~g}$ per $\mathrm{kg}$ body weight per day $(\mathrm{n}=8)$, to two different subsets of rats via drinking water in their cage from GD10 through to GD20. Drinking water containing STS was prepared based on weight gain over the previous three days and based on each rat's average daily water consumption over the previous three days. In other words, every three days, the STS concentration in drinking bottles was reformulated to account for gestational weight gain and possible changes in water intake throughout pregnancy to ensure that each individual rat was ingesting the appropriate dose. Due to this administration route, shared housing was no longer possible after the start of the treatment. The chosen dose was based on a pilot study performed in female rats (Figure A1 in Appendix A).

\subsubsection{Renal Injury Measurements}

The rats were placed in metabolic cages for $24 \mathrm{~h}$ urine collection on two occasions, prior to mating (baseline) and at end of pregnancy (from GD19 to 20). Sodium azide (Fisher Chemical, Inc, Waltham, MA, USA) was added to the urine collection container to prevent bacterial growth. Urinary protein concentration was measured using the Bradford Assay (BioRad Laboratories, Hercules, CA, USA), and proteinuria was defined as $>20 \mathrm{mg} / 24 \mathrm{~h}$. Urea was measured colorimetrically (DiaSys Diagnostic Systems, GmbH, Holzheim, Germany) in plasma obtained on GD20.

\subsubsection{Uterine Artery Resistance Index}

Uterine artery power Doppler velocimetry measurements were performed under isoflurane anesthesia/1LO 2 (NDC11695-6776-2, Henry Schein Animal Health, Dublin, OH, USA; induction with $3 \%$ and maintenance with $1.5 \%$ to $2 \%$ ) in all rats with a Vevo 3100 (FUJIFILM VisualSonics, Inc, Toronto, ON, Canada) using a $30 \mathrm{~Hz}$ transducer on GD18. The Doppler waveform of the uterine artery was recorded. The peak systolic flow velocity (PSV) and end-diastolic flow velocity (EDV) values of three waves per location were determined to calculate the uterine artery resistance index (UARI) as follows: $\mathrm{UARI}=(\mathrm{PSV}-\mathrm{EDV}) / \mathrm{PSV}$. UARI was determined bilaterally at two to three different locations along the uterine artery, from which mean UARI was calculated.

\subsubsection{Terminal Mean Arterial Pressure (MAP) Measured under Anesthesia}

At the time of tissue harvesting, rats were anesthetized using isoflurane (induction with $3 \%$ and maintenance with $2 \%$ ). The terminal MAP (primary outcome) in all rats in the three groups (control and two different STS dosages) was measured via the abdominal aorta. MAP measurements were 
recorded using the PowerLab system with the LabChart software (ADInstruments, Sydney, Australia), and a MLT0699 Disposable BP Transducer (ADinstruments) that was calibrated daily. The use of anesthetized terminal blood pressure was considered a valid method for assessing hypertension in rats [21]. Accompanying heart rate was determined.

\subsubsection{Tissue and Blood Collection}

Tissue collection was performed on GD20. A terminal blood sample was extracted from the abdominal aorta, after which the organs were perfused blood free with phosphate-buffered saline. The number of viable and resorbed fetuses in each uterine horn was noted. Subsequently, placental weight, fetal weight, and crown-rump length for each viable fetus was recorded and averaged per litter. Fetal/placental weight ratio was calculated for each individual unit before averaging per litter. Kidneys, hearts, and spleens were blotted dry on filter paper and, then, weighed. Hematocrit was determined using glass micro-hematocrit heparinized capillary tubes and Sorvall Legend Micro 17 microcentrifuge (Fisher Scientific, Inc, Waltham, MA, USA).

\subsubsection{Plasma and Urinary Thiosulfate and Sulfate Concentration}

The concentrations of thiosulfate $\left(\mathrm{S}_{2} \mathrm{O}_{3}{ }^{2-}\right)$ and sulfate $\left(\mathrm{SO}_{4}{ }^{2-}\right)$ in the $24 \mathrm{~h}$ urine collected at the end of pregnancy (GD19 and GD20) and in plasma collected on GD20 were determined by ion chromatography with mass spectrometry detection using a reagent-free high-pressure Dionex ${ }^{\mathrm{TM}}$ ICS-5000 MSQ system attached to an AS-AP autosampler (Thermo Fisher Scientific, Hemel Hempstead, UK). Thiosulfate and sulfate were separated from other anions present in the samples using a Dionex IonPac AS16 $2 \times 250 \mathrm{~mm}$ analytical column, protected by an AG16 $2 \times 50 \mathrm{~mm}$ guard column, both kept at a constant temperature of $30^{\circ} \mathrm{C}$. An eluent generator with a potassium hydroxide $(\mathrm{KOH})$ cartridge was used to produce the following gradient: $20 \mathrm{mM}$ from 0.1 to $4.0 \mathrm{~min}$, followed by $30 \mathrm{mM}$ until $8.0 \mathrm{~min}$ at a constant flow rate of $0.38 \mathrm{~mL} / \mathrm{min}$. Total run time was $10 \mathrm{~min}$ with retention times of $4.2 \mathrm{~min}$ and $6.1 \mathrm{~min}$ for sulfate and thiosulfate, respectively. The injection volume was $2.5 \mu \mathrm{L}$. The system was equipped with an Anion Electrolytically Regenerated Suppressor (AERS 500e, 2 mm) with an applied current of $29 \mathrm{~mA}$. The quadrupole detector was coupled to the IC via an electrospray ionization interface (ESI) and operated in negative SIM mode at 97 and $113 \mathrm{~m} / \mathrm{z}$ for the monoprotonated anions of sulfate and thiosulfate, respectively. The capillary voltage was maintained at $2.5 \mathrm{kV}$, while the cone voltages were $70 \mathrm{~V}$ and $55 \mathrm{~V}$ for sulfate and thiosulfate, respectively. Probe temperature was kept at $500{ }^{\circ} \mathrm{C}$. Prior to analysis, samples were subjected to ultrafiltration using Amicon ${ }^{\complement}$ Ultra $^{\circ}$ Centrifugal Filters with a $10 \mathrm{kD}$ cut-off to remove proteins. The membrane of these filters was found to retain a considerable portion of sulfate and thiosulfate, in particular in the low concentration range. Therefore, all calibration standards used for quantification were also subjected to ultrafiltration prior to injection to account for analyte loss using this sample processing method. Detector responses were found to be linear up to concentrations of $25 \mu \mathrm{M}$ with a detection limit of approximately $100 \mathrm{nM}$ (S/N $\geq 3$ ) for either anion. Daily urinary excretion values were calculated from the molar concentrations of either anion taking total volumes of the urines collected into account.

\subsubsection{Renal Histology}

One longitudinal section of the left kidney was immersed in 10\% buffered formalin for $48 \mathrm{~h}$, after which it was immersed in $70 \%$ ethanol until embedment in paraffin. The paraffin-embedded kidney sections were cut into $4 \mu \mathrm{m}$ sections and stained with periodic acid staining (PAS). Focal glomerulosclerosis (FGS) and interstitial fibrosis were scored by a blinded investigator. FGS lesions were scored positive by the presence of focal and segmental glomerular scarring and also obliteration of the glomerular capillaries with enhanced mesangial matrix expansion and adhesion formation between the tuft and the capsule of Bowman. The severity of FGS was scored in a semiquantitative manner on a scale of 0 to $4+$ in PAS stained sections. Fifty glomeruli were scored and the average per animal was expressed as percentages. Thus, the maximum score for FGS lesions was 400\% [22]. 
Interstitial fibrosis was scored by the presence of significant interstitial broadening of the peritubular area combined with loss of the integrity of the tubular basement membrane. Kidneys were scored for the percentage of involvement as follows: 0 to $5 \%, 5 \%$ to $10 \%, 10 \%$ to $25 \%, 25 \%$ to $50 \%$, and $50 \%$ to 100\%. Mean glomerular area was determined in Aperio ImageScope (v12.1.0.5029, Leica Biosystems, Dublin, Ireland) by encircling the capsule of Bowman of 50 glomeruli per kidney. The urinary space was calculated by subtracting the glomerular tuft area from the individual glomerular area. We lost one kidney histology sample from a dam treated with STS at $3 \mathrm{~g}$ per $\mathrm{kg}$ body weight per day.

\subsubsection{Placental Histology}

One placenta per rat was randomly selected for paraffin embedding (similar procedure as for the kidneys). Placentas were cut transverselyin, the center as $4 \mu \mathrm{m}$ sections, and stained with hematoxylin and eosin (HE). The area of labyrinth and basal zone were visually determined as the first layer mostly consists of trophoblasts and the second layer of spongiotrophoblasts [23]. The investigator was blinded to the groups. Due to cutting artifacts, determination of the layers was not possible in one placenta of the control group and one placenta from the $2 \mathrm{~g}$ STS group.

\subsubsection{Statistical Analyses}

All data were analyzed using GraphPad Prism 8.0.1 (GraphPad Software, Inc., San Diego, CA, USA). Data were determined to be parametric or non-parametric using Shapiro-Wilk. Statistical analyses were performed using one-way ANOVA with Dunnett's multiple comparison (parametric data) or Kruskal-Wallis test (non-parametric data). The thiosulfate and sulfate concentrations were tested with Brown-Forsythe and Welch ANOVA with Dunnett's multiple comparison. Data were presented as mean \pm S.E.M unless stated otherwise. A two-sided p-value below 0.05 was considered significant. The experimental unit was an individual pregnant dam. A priori power calculation was based on that a MAP difference of $5 \mathrm{mmHg}$ (primary outcome) would be of clinical interest (effect size $\mathrm{f}=2.5$ ), with a power of 0.95 , alpha of 0.05 , three groups resulted total sample size of 9 (G*Power 3.1.9, Düsseldorf, Germany).

\section{Results}

\subsection{Effect of STS Treatment on Renal Function Parameters}

Our lab previously showed that proteinuria in healthy Sprague-Dawley rat is $12 \pm 3 \mathrm{mg} / 24 \mathrm{~h}$ during late pregnancy [20]. Treatment with $2 \mathrm{~g}$ STS per $\mathrm{kg}$ body weight per day had no effect on proteinuria on GD19 nor on plasma urea on GD20 (Table 1). Treatment with $3 \mathrm{~g}$ STS per kg body weight per day resulted in significantly higher proteinuria on GD19 as compared with controls $(89 \pm 15 \mathrm{mg} / 24 \mathrm{~h}$ vs. $56 \pm 5 \mathrm{mg} / 24 \mathrm{~h}, p=0.03)$. Water consumption and urine production (ml/kg/hour) were not significantly different between the treatment groups (Table 1).

Table 1. Renal function parameters at the end of pregnancy.

\begin{tabular}{ccccc}
\hline Parameter & $\begin{array}{c}\text { CON } \\
(\mathbf{n}=\mathbf{1 3})\end{array}$ & $\begin{array}{c}\text { STS (2 g) } \\
(\mathbf{n}=\mathbf{9})\end{array}$ & $\begin{array}{c}\text { STS (3 g) } \\
(\mathbf{n}=\mathbf{8})\end{array}$ & $p$-Value \\
\hline Water intake (mL) GD19 & $42.7 \pm 1.9$ & $48.0 \pm 3.2$ & $42.3 \pm 3.6$ & 0.30 \\
Urine production GD19 (mL/kg BW per hour) & $2.20 \pm 0.2$ & $2.21 \pm 0.3$ & $1.89 \pm 0.1$ & 0.59 \\
Proteinuria GD19 (mg/24h) & $56 \pm 5^{\mathrm{a}}$ & $51 \pm 8$ & $89 \pm 15^{\mathrm{a}}$ & 0.02 \\
Urea plasma GD20 (mmol/L) & $7.7 \pm 0.2$ & $8.5 \pm 0.6$ & $8.4 \pm 0.6$ & 0.57 \\
Body weight (grams) GD19 & $306 \pm 4$ & $316 \pm 7$ & $294 \pm 3$ & 0.02 \\
Gestational weight gain GD0-19 (\%) & $32.5 \pm 1.9$ & $37.9 \pm 1.7$ & $24.3 \pm 1.6$ & $<0.001$ \\
\hline
\end{tabular}

STS dose in grams STS per kg body weight per day. The $p$-value from one-way ANOVA is provided with similar superscripted letters indicating which treatment groups was significantly different from the control group in Dunnett's multiple comparisons test. Data presented as mean \pm S.E.M. CON, control; GD, gestational day; and STS, sodium thiosulfate. 


\subsection{Effect of STS Treatment on Uterine Artery Resistance Index}

The UARI in healthy Sprague-Dawley rats is $0.55 \pm 0.02$ at the end of pregnancy [20]. In this study we, again, observed elevated UARI with characteristic notching in the ultrasound waveforms in the Dahl S dams (Figure 1a-c). Although there was a treatment effect across the groups $(p=0.03)$, UARI was not different when treatments with $2 \mathrm{~g}$ and $3 \mathrm{~g}$ STS per $\mathrm{kg}$ body weight per day were compared with the control (respectively, $p=0.15$ and $p=0.31$, Figure $1 \mathrm{~d}$ ).
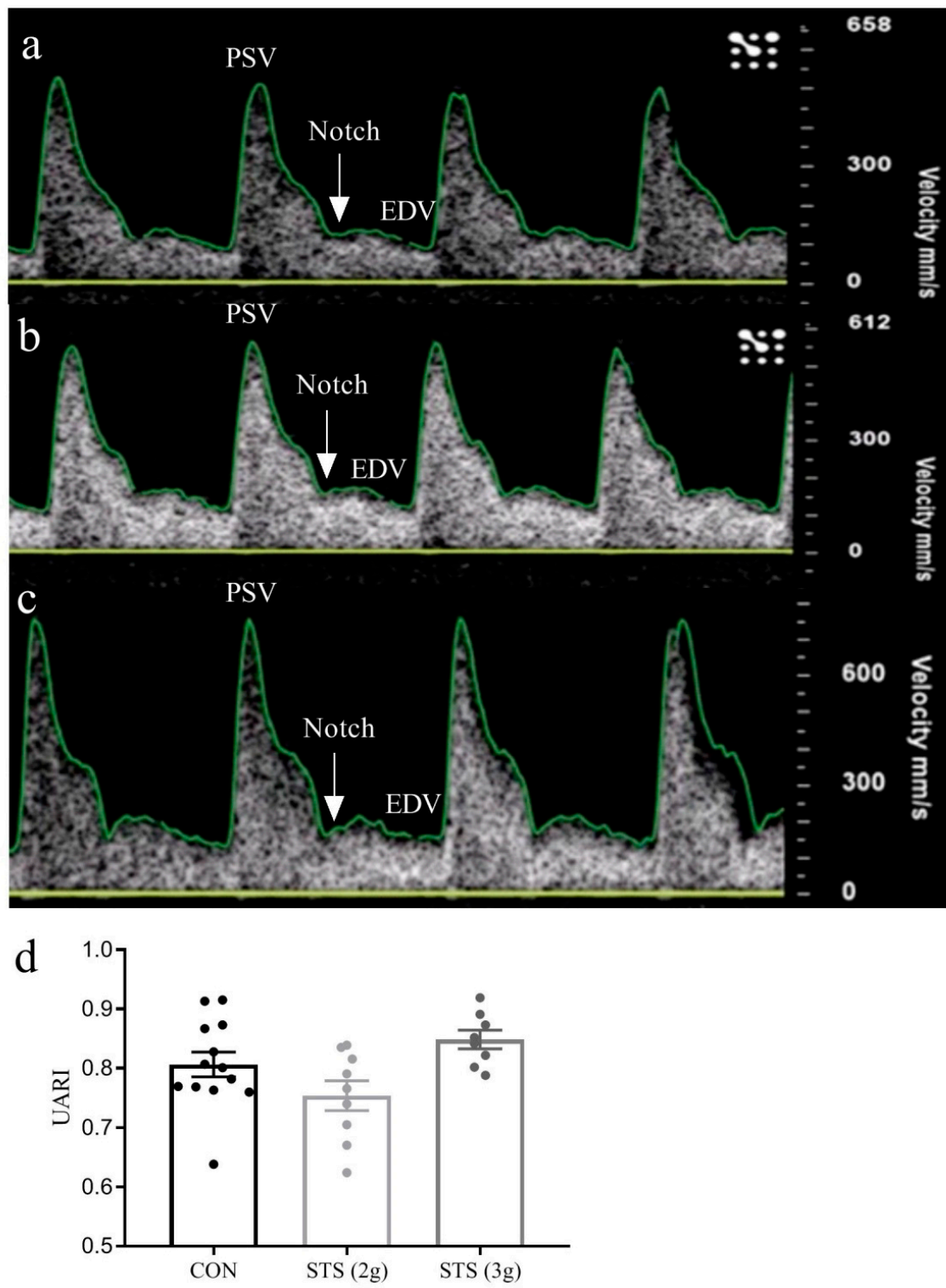

Figure 1. Uterine artery resistance index on GD18. Examples of Doppler waveforms in a (a) control dam; (b) dam treated with $2 \mathrm{~g}$ STS per $\mathrm{kg}$ body weight per day; and (c) dam treated with $3 \mathrm{~g}$ STS per $\mathrm{kg}$ body weight per day, white arrows indicate notching; (d) treatment with $2 \mathrm{~g}$ STS $(\mathrm{n}=9)$ and $3 \mathrm{~g}$ STS $(\mathrm{n}=8)$ showed no significant difference in UARI as compared with the control $(\mathrm{n}=13)$ with persistence of characteristic notching tested with one-way ANOVA Dunnett's multiple comparisons test, data presented as mean \pm S.E.M. CON, control; EDV, end-diastolic flow velocity; GD, gestational day; PSV, peak systolic flow velocity; STS, sodium thiosulfate; UARI, uterine artery resistance index; $2 \mathrm{~g}$, $2 \mathrm{~g}$ per $\mathrm{kg}$ body weight per day; and $3 \mathrm{~g}$, $3 \mathrm{~g}$ per $\mathrm{kg}$ body weight per day. 


\subsection{Effect of STS Treatment on MAP}

During late pregnancy, Sprague-Dawley rats had a MAP of $97 \pm 6 \mathrm{mmHg}$ [24] with a heart rate of $326 \pm 15$ [unpublished data] when measured under anesthesia. Terminal MAP (under anesthesia) was not different between pregnant Dahl rats treated with $2 \mathrm{~g}$ STS per $\mathrm{kg}$ body weight per day and the control $(135.9 \pm 6.6$ vs. $136.3 \pm 2.9 \mathrm{mmHg}, p=0.99$, Figure 2$)$. In contrast, Dahl S rats treated with $3 \mathrm{~g}$ STS per kg body weight per day, demonstrated a significant decrease in terminal MAP as compared with the control group (121.8 \pm 3.0 vs. $136.3 \pm 2.9 \mathrm{mmHg}, p<0.05$, Figure 2$)$. Heart rate was also decreased in a dose-dependent manner following STS treatment, $\mathrm{CON}(\mathrm{n}=10) 359 \pm 7 \mathrm{bpm}$ versus STS $2 \mathrm{~g}(\mathrm{n}=7) 333 \pm 9 \mathrm{bpm}$ versus STS $3 \mathrm{~g}(\mathrm{n}=8) 321 \pm 8 \mathrm{bpm}(p=0.006$, Dunnett's multiple comparison CON vs. STS $2 \mathrm{~g} p=0.07$ and CON vs. 8 STS $3 \mathrm{~g} p=0.004)$.

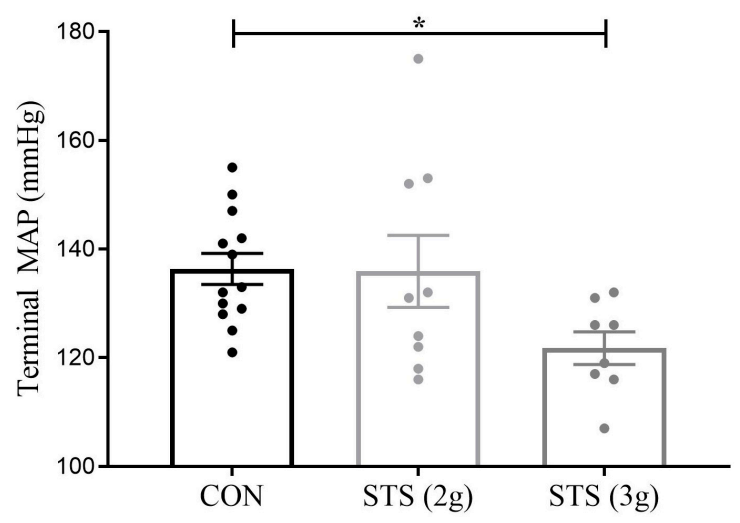

Figure 2. Mean arterial pressure in the Dahl S rat treated with STS versus control. MAP was not different between $2 \mathrm{~g}$ STS per $\mathrm{kg}$ body weight per day $(\mathrm{n}=9)$ and the control $(\mathrm{n}=13)$ but was significantly reduced by $3 \mathrm{~g}$ STS per kg body weight per day $(n=8)$ as compared with the control dams tested with one-way ANOVA Dunnett's multiple comparisons test. MAP, mean arterial pressure; CON, control; STS, sodium thiosulfate; $2 \mathrm{~g}$, $2 \mathrm{~g}$ per kg body weight per day; and $3 \mathrm{~g}, 3 \mathrm{~g}$ per kg body weight per day. Data presented as mean \pm S.E.M. ${ }^{*} p<0.05$.

\subsection{Effect of STS Treatment on Fetal and Placental Outcomes}

Our lab previously showed that fetal weight was $2.46 \pm 0.17 \mathrm{~g}$, crown-rump length $3.20 \pm 0.09$ $\mathrm{cm}$, viable litter size of $13.7 \pm 0.58$, fetal resorption of $0.47 \% \pm 046 \%$, placental weight $0.56 \pm 0.01 \mathrm{~g}$, and fetal/placental weight ratio of $4.49 \pm 0.30$ in healthy Sprague-Dawley rats on GD20 [20]. Dahls S rats showed lower fetal weight, length, litter size, and placental weight, and higher fetal resorption and fetal/placental weight ratio (Table 2). STS treatment did not affect fetal weight, fetal crown-rump length, litter size, or fetal demise. In addition, placental weight did not differ among groups. However, treatment with STS caused a decrease in fetal/placental weight ratio in the Dahl S rat administered $3 \mathrm{~g}$ per kg body weight per day $(3.83 \pm 0.07$ vs. $4.31 \pm 0.08 ; p<0.01)$.

Table 2. Effect of STS treatment on fetal and placental outcomes.

\begin{tabular}{ccccc}
\hline Fetal and Placental Outcome & $\begin{array}{c}\text { CON } \\
(\mathbf{n = 1 3 )}\end{array}$ & $\begin{array}{c}\text { STS (2 g) } \\
(\mathbf{n}=\mathbf{9})\end{array}$ & $\begin{array}{c}\text { STS (3 g) } \\
(\mathbf{n}=\mathbf{8})\end{array}$ & $\boldsymbol{p}$-Value \\
\hline Fetal weight (g) & $2.13 \pm 0.04$ & $2.13 \pm 0.07$ & $2.01 \pm 0.05$ & 0.28 \\
Fetal crown-rump length (cm) & $3.06 \pm 0.04$ & $3.03 \pm 0.05$ & $3.11 \pm 0.03$ & 0.51 \\
Viable litter size (n) & $10.71 \pm 0.6$ & $11.2 \pm 0.5$ & $11.3 \pm 0.4$ & 0.68 \\
Fetal resorptions (\%) & $8.4 \pm 1.9$ & $5.9 \pm 2.4$ & $3.0 \pm 1.5$ & 0.24 \\
Placental weight (g) & $0.50 \pm 0.01$ & $0.51 \pm 0.01$ & $0.53 \pm 0.01$ & 0.14 \\
Fetal/placental weight ratio & $4.31 \pm 0.08^{\text {a }}$ & $4.27 \pm 0.16$ & $3.83 \pm 0.07^{\text {a }}$ & $<0.01$ \\
\hline
\end{tabular}

STS dose in grams STS per kg body weight per day. The $p$-value from one-way ANOVA is provided with similar superscripted letters indicating which treatment groups was significantly different from the control group in Dunnett's multiple comparisons test. Data presented as mean \pm S.E.M. CON, control; STS, sodium thiosulfate. 


\subsection{Effect of STS Treatment on Gestational Weight Gain and Organ Weight}

STS administered at $2 \mathrm{~g}$ per $\mathrm{kg}$ body weight per day showed no effect on relative renal and heart weight (Table 3). When administered at $3 \mathrm{~g}$ per $\mathrm{kg}$ body weight per day, STS resulted in a higher relative total kidney weight as compared with the control groups $(0.86 \pm 0.04 \%$ vs. $0.72 \pm 0.02 \%$, $p<0.01)$. Gestational weight gain from GD0-19 was lower in the $3 \mathrm{~g}$ STS treated group as compared with the control group (Table 1).

Table 3. Organ weight and hematocrit on GD20.

\begin{tabular}{ccccc}
\hline Parameter & CON $(\mathbf{n}=\mathbf{1 3})$ & 2 g STS $(\mathbf{n}=\mathbf{9 )}$ & 3 g STS $(\mathbf{n}=\mathbf{8})$ & $p$-Value \\
\hline Relative total kidney weight (\%) & $0.72 \pm 0.02^{\mathrm{a}}$ & $0.75 \pm 0.03$ & $0.86 \pm 0.04^{\mathrm{a}}$ & $<0.01$ \\
Relative heart weight (\%) & $0.34 \pm 0.004$ & $0.35 \pm 0.01$ & $0.33 \pm 0.01$ & 0.28 \\
Relative splenic weight (\%) & $0.28 \pm 0.01$ & $0.30 \pm 0.01$ & $0.31 \pm 0.01$ & 0.07 \\
Hematocrit (\%) & $36.5 \pm 1.7$ & $38.4 \pm 0,9$ & $33.4 \pm 2.1$ & 0.18 \\
\hline
\end{tabular}

STS dose in grams STS per kg body weight per day. The $p$-value from one-way ANOVA is provided with similar superscripted letters indicating which treatment groups was significantly different from the control group in Dunnett's multiple comparisons test. Data presented as mean \pm S.E.M. CON, control; GD, gestational day; STS, sodium thiosulfate.

\subsection{Plasma and Urinary Thiosulfate and Sulfate Concentration}

Plasma concentrations and daily urinary excretion values for thiosulfate and sulfate increased in a dose-dependent manner with STS administration (Figure 3).
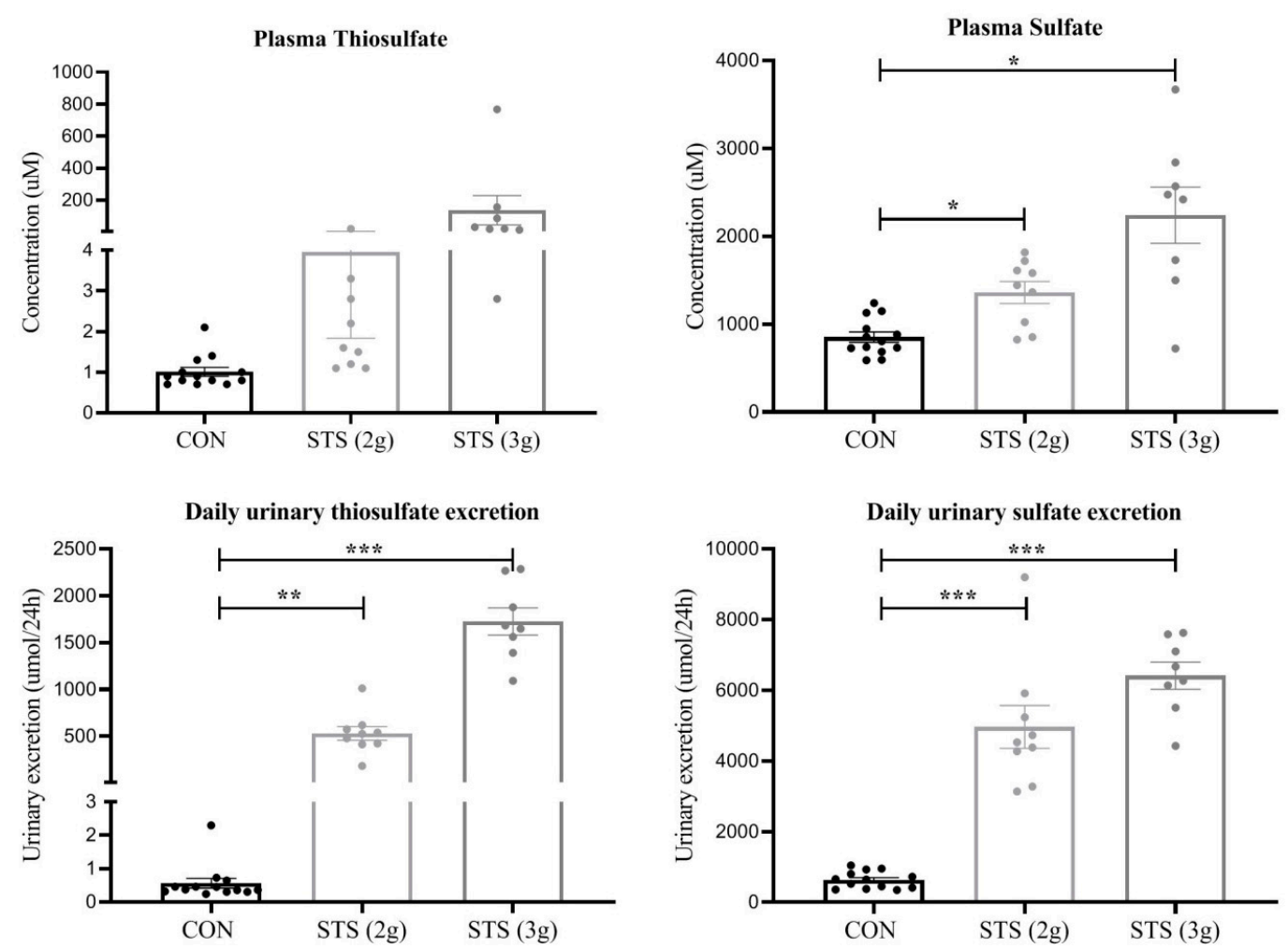

Figure 3. Plasma concentration and daily urinary excretion of thiosulfate and sulfate in the Dahl S rat treated with STS versus a control. Plasma concentrations and urinary excretion between the control dams $(n=13)$ and treated dams dosed at $2 \mathrm{~g}$ STS per $\mathrm{kg}$ body weight per day $(n=9)$ or $3 \mathrm{~g}$ STS per $\mathrm{kg}$ body weight per day $(\mathrm{n}=8)$ were tested with Brown-Forsythe and Welch ANOVA and Dunnett's multiple comparison test. CON, control; STS, sodium thiosulfate; 2 g, 2 g per kg body weight per day; and $3 \mathrm{~g}, 3 \mathrm{~g}$ per $\mathrm{kg}$ body weight per day. Data presented as mean \pm S.E.M. ${ }^{*} p<0.01 ;{ }^{* *} p<0.001$; *** $p<0.0001$. 
When we evaluated the plasma concentrations and urinary excretions levels, independent of the groups, we found that plasma thiosulfate correlated most strongly with MAP (Table 4).

Table 4. Spearman's rho correlation between thiosulfate and sulfate and mean arterial pressure.

\begin{tabular}{ccc}
\hline Sample $(\mathbf{n}=\mathbf{3 0})$ & $\boldsymbol{r}$ & $\boldsymbol{p}$-Value \\
\hline Plasma thiosulfate $(\mathrm{uM})$ & -0.62 & $<0.001$ \\
\hline Plasma sulfate concentration $(\mathrm{uM})$ & -0.26 & 0.17 \\
\hline Urinary thiosulfate excretion $(\mathrm{umol} / 24 \mathrm{~h})$ & -0.43 & 0.02 \\
\hline Urinary sulfate excretion $(\mathrm{umol} / 24 \mathrm{~h})$ & -0.45 & 0.01 \\
\hline
\end{tabular}

\subsection{Effect of STS Treatment on Glomerular Injury}

A previous study in our lab showed glomerulomegaly in pregnant Dahl $S$ rats as compared with pregnant Sprague-Dawley rats [20]. Histological evaluation of kidneys collected in our study showed that renal damage caused by pregnancy in the Dahl $S$ rat was neither ameliorated nor exacerbated by $2 \mathrm{~g}$ or $3 \mathrm{~g}$ STS per $\mathrm{kg}$ body weight per day STS (Figure A2 and Table 5). Interstitial fibrosis was $<5 \%$ in all cases and no vessel abnormalities were observed.

Table 5. Histology scoring of kidney injury.

\begin{tabular}{ccccc}
\hline Kidney Injury Scoring Parameter & $\begin{array}{c}\text { CON } \\
(\mathbf{n}=\mathbf{1 3})\end{array}$ & $\begin{array}{c}\text { STS 2 g } \\
(\mathbf{n}=\mathbf{9 )}\end{array}$ & $\begin{array}{c}\text { STS 3 g } \\
(\mathbf{n}=7)\end{array}$ & $\boldsymbol{p}$-value \\
\hline Glomerulosclerosis damage score $(\%)$ & $15.2 \pm 2.5$ & $10.2 \pm 3.3$ & $14.0 \pm 5.8$ & 0.58 \\
Glomerular area $\left(\mu \mathrm{m}^{2}\right)$ & $10,906 \pm 421$ & $11,443 \pm 516$ & $10,279 \pm 410$ & 0.29 \\
Glomerular tuft $\left(\mu^{2}\right)$ & $8944 \pm 355$ & $9390 \pm 439$ & $8502 \pm 364$ & 0.37 \\
Urinary space $\left(\mu \mathrm{m}^{2}\right)$ & $1962 \pm 84$ & $2053 \pm 129$ & $1777 \pm 155$ & 0.31 \\
\hline
\end{tabular}

STS dose in grams STS per kg body weight per day. Histological evaluation of kidneys showed that glomerulosclerosis in the control pregnant Dahl S rat $(n=13)$ was neither ameliorated nor exacerbated by either $2 \mathrm{~g}(\mathrm{n}=9)$ or $3 \mathrm{~g}(\mathrm{n}=7)$ STS per kg body weight per day. Data presented as mean \pm S.E.M. CON, control; STS, sodium thiosulfate.

\subsection{Effect of STS Treatment on Placenta Histomorphology}

A previous study reported that the labyrinth zone is $22.1 \mathrm{~mm}^{2}$ and the basal zone is $5.0 \mathrm{~mm}^{2}$ in Sprague-Dawley rats on GD19.5 [23]. There were no differences in the (proportional) layers across groups (Table 6 and Figure A2).

Table 6. Histology scoring of the placenta.

\begin{tabular}{|c|c|c|c|c|}
\hline Placental Histology Scoring Parameter & $\begin{array}{c}\mathrm{CON} \\
(\mathrm{n}=12)\end{array}$ & $\begin{array}{l}\text { STS } 2 \mathrm{~g} \\
(\mathrm{n}=8)\end{array}$ & $\begin{array}{l}\text { STS } 3 g \\
(n=8)\end{array}$ & $p$-Value \\
\hline Labyrinth zone $\left(\mathrm{mm}^{2}\right)$ & $21.89 \pm 0.74$ & $20.60 \pm 0.95$ & $21.64 \pm 1.45$ & 0.65 \\
\hline Basal zone $\left(\mathrm{mm}^{2}\right)$ & $7.61 \pm 0.44$ & $6.9 \pm 0.85$ & $8.67 \pm 0.57$ & 0.17 \\
\hline $\begin{array}{c}\text { Proportion labyrinth zone of whole fetal } \\
\text { placental area (\%) }\end{array}$ & $74 \pm 1$ & $76 \pm 2$ & $71 \pm 1$ & 0.22 \\
\hline $\begin{array}{c}\text { Proportion basal zone of whole fetal } \\
\text { placental area }(\%)\end{array}$ & $26 \pm 1$ & $25 \pm 2$ & $29 \pm 1$ & 0.22 \\
\hline
\end{tabular}

STS dose in grams STS per kg body weight per day. Morphological evaluation of placentas showed no difference in the control pregnant Dahl $\mathrm{S}$ rat as compared with either $2 \mathrm{~g}$ or $3 \mathrm{~g}$ STS per kg body weight per day. Data presented as mean \pm S.E.M. CON, control; STS, sodium thiosulfate.

\section{Discussion}

This study shows that prenatal administration of STS at $2 \mathrm{~g}$ per $\mathrm{kg}$ body weight per day did not improve or worsen the PE or FGR phenotype in the Dahl S rat. Administration of STS at $3 \mathrm{~g}$ per $\mathrm{kg}$ 
body weight per day, however, did reduce maternal blood pressure, but also exacerbated proteinuria, increased renal weight, reduced gestational weight gain, and decreased the fetal/placental weight ratio.

Maternal hypertension is the cardinal feature of $\mathrm{PE}$ and the main reason that iatrogenic premature delivery is required. We observed that STS administered at $2 \mathrm{~g}$ per $\mathrm{kg}$ body weight per day was insufficient to reduce maternal blood pressure. However, when dosed at $3 \mathrm{~g}$ per $\mathrm{kg}$ body weight per day, STS significantly reduced maternal blood pressure by $14 \mathrm{mmHg}$. This is clinically interesting because reduced maternal blood pressure would allow the prolongation of preeclamptic pregnancies, which would benefit fetal outcomes. Water intake and urine production, as measured on GD19, and hematocrit as measured on GD20, did not differ between the groups, and as such, the observed reduction in MAP does not appear attributable to hypovolemia. However, heart rate was also dose-dependently reduced in the treated groups versus the control group. As the induction and maintenance of anesthesia was similar, this would seem to suggest increased parasympathetic sensitivity. The inverse correlation between plasma levels and urinary excretion rates of thiosulfate and sulfate and arterial pressure was strongest for plasma thiosulfate, suggesting direct vasodilation. STS has not been tested in a PE setting before, our findings are in line with a previous study that demonstrated STS's antihypertensive effect in an angiotensin-II male rat model of cardiac disease, and further substantiate a large body of literature that implicates a deficit in $\mathrm{H}_{2} \mathrm{~S}$ in the pathophysiology of hypertension $[9,16,25,26]$. However, $\mathrm{N}$-acetyl-1-cysteine (NAC), the only $\mathrm{H}_{2} \mathrm{~S}$ stimulator tested to date in pregnant humans, failed to ameliorate PE in humans [27]. The beneficial effects from our study, therefore, cannot be attributed with certainty to $\mathrm{H}_{2} \mathrm{~S}$ production alone, but potentially combined with other effects caused by STS.

Proteinuria is another hallmark feature of PE. Dosed at $2 \mathrm{~g}$ per $\mathrm{kg}$ body weight per day, STS had no significant effect on gestational proteinuria. However, exacerbated proteinuria and renal enlargement were observed in the dams treated with STS at a dose of $3 \mathrm{~g}$ per $\mathrm{kg}$ body weight per day. To our knowledge, the detrimental renal effects after treatment with $\mathrm{H}_{2} \mathrm{~S}$ have not been described previously, nor has reduced gestational weight after prenatal administration of $\mathrm{H}_{2} \mathrm{~S}$ donors been reported. However, in previous studies, STS was administered only once or twice throughout the respective studies and dosed at concentrations ranging from 0.5 to $2.0 \mathrm{~g}$ per $\mathrm{kg}$ body weight in animal studies and up to $25 \mathrm{~g}$ in nonpregnant human studies [16,28,29]. In our study, the drug was administered more frequently as compared with these previous studies, and consequently, plasma concentrations and urinary excretions of thiosulfate and sulfate reached very high levels in a dose-dependent manner. Although the higher dose combined with the longer administration period could have resulted in toxic effects in the kidney, especially in the Dahl S rat that is susceptible to renal injury, histological examination of glomerulosclerosis or glomerular area did not show differences between the treated and untreated group.

The presence of FGR as another consequence of placental insufficiency is mimicked by the Dahl $S$ rat, and the fetal weight in our untreated group was comparable with the reduced fetal weight described previously [20,30]. When administered at $3 \mathrm{~g}$ per $\mathrm{kg}$ body weight per day, STS caused a decrease in fetal/placental weight ratio. This decrease suggests worsening of placental insufficiency; however, this is difficult to conclude in the absence of changes in uterine artery blood flow, fetal weight, placental weight, or area of placental layers. While treating hypertensive disorders of pregnancy could result in prolongation of gestation, antihypertensive drugs, such as labetalol, have been associated with an increased risk of FGR; this detrimental effect is possibly due to a sudden overcorrected blood pressure resulting in (temporarily) decreased uteroplacental blood flow, and therefore impaired fetal growth [31,32]. Effects of STS on fetal outcomes in animal models of healthy pregnancy or PE have not been studied previously.

Thiosulfate uptake occurs in the gastrointestinal tract and, after circulating, is either excreted by the kidneys or oxidized by mitochondria [17,33,34]. In the presence of hydroxyl radicals or peroxides, STS can react with GSSG (oxidized glutathione) resulting in reduced glutathione [17]. Furthermore, STS also has potential to produce hydrogen sulfide by its reaction with trans-sulfuration enzymes, such as thiosulfate sulfur transferase can also convert thiosulfate to $\mathrm{H}_{2} \mathrm{~S}$ [33]. We made use of this 
mitochondrial oxidation pathway to confirm bioavailability after oral application, as we were not able to measure $\mathrm{H}_{2} \mathrm{~S}$ as such. Urinary excretion of thiosulfate and sulfate was elevated above baseline in both treatment groups, showing that thiosulfate was absorbed well. Interestingly, plasma thiosulfate concentrations in dams of the $2 \mathrm{~g}$ STS group overlapped with those of the control group, while the $3 \mathrm{~g}$ STS group showed a much more robust increase. This suggests that the chosen daily STS dose of $2 \mathrm{~g}$ per kg body weight was at the border of regulatory (not metabolic) capacity in pregnant Dahl S rats. Plasma sulfate concentrations, however, revealed a clearer dose proportionality, indicating that most thiosulfate was oxidized

Our study had various strengths. This was the first time that the antihypertensive potential of STS was tested in a (complicated) pregnancy setting and the first time that a H2S donor was tested as a potential therapeutic candidate in a spontaneous animal model of PE. In addition, STS's oral administration route was a highly desirable choice in terms of potential clinical implementation and indeed turned out to be a highly efficient route. We tested two doses of STS. Finally, the effect of a $\mathrm{H}_{2} \mathrm{~S}$ donor on UARI was evaluated as a potential mechanism by which $\mathrm{H}_{2} \mathrm{~S}$ exerts its effects.

While we ensured adequate intake of STS to the best of our capability by adjusting the concentration of STS in drinking water every three days, we acknowledge the limitation of the oral administration route regarding certainty of the exact dose. However, the very high concentrations of thiosulfate and sulfate measured in plasma and urine documented successful STS intake and efficient metabolic conversion. We also could not compare the bioavailability by oral route versus intraperitoneal injection. We could not determine whether the reduced gestational weight gain in the $3 \mathrm{~g}$ STS group was attributed to reduced food intake as this was not measured.

\section{Future Perspectives}

STS administered at $3 \mathrm{~g}$ per $\mathrm{kg}$ body weight per day appears to reduce maternal MAP, which holds promise for prolongation of preeclamptic pregnancies, and thus fetal outcomes. The $\mathrm{H}_{2} \mathrm{~S}$ pathway remains a promising target of research in the search for much needed treatment options for preeclampsia and fetal growth restriction. However, the $\mathrm{H}_{2} \mathrm{~S}$ donor, $\mathrm{STS}$, at this dose, appears to worsen placental insufficiency and proteinuria, and to cause kidney enlargement after long-term daily treatment, and thus cannot be recommended for implementation in clinical practice for pregnancy-related diseases at this stage. Further tests are needed to shed light on how STS influences healthy pregnancies and pregnancies complicated by placental insufficiency, and whether the duration of treatment plays a role regarding potential detrimental outcomes. To gain conclusive insight and understand of the mechanisms of action underlying our detrimental findings, future studies should apply STS in other models of PE to determine whether STS can be beneficial. In both female and male Dahl S rats, studies should focus on mechanisms of renal enlargement and worsening of proteinuria to determine if this is a pregnancy-specific effect.

\section{Conclusions}

This is the first study to test STS in a spontaneous rat model of preeclampsia and fetal growth restriction. Daily administration at $3 \mathrm{~g}$ per $\mathrm{kg}$ body weight reduced maternal blood pressure, holding promise for prolongation of preeclamptic pregnancies, and thus fetal outcomes. However, we also found deleterious effects, including worsening of proteinuria and placental insufficiency. Hence, STS cannot be recommended for clinical use during pregnancy at this stage.

Author Contributions: Conceptualization, A.T.L., S.M.C., J.M.S., and F.T.; methodology, A.T.L., S.M.C., J.M.S., J.A.J., and F.T.; software, N/A; validation, S.M.C., J.M.S., and F.T.; formal analysis, S.M.C. and F.T.; investigation, S.M.C., J.M.S., C.A.R., H.v.G., M.M., M.F., and F.T.; Resources, J.M.S., M.R.G., and H.v.G.; data curation, S.M.C., C.A.R., and F.T.; writing-original draft preparation, S.M.C. and F.T.; writing-review and editing, A.T.L., J.M.S., J.A.J., H.v.G.., M.R.G., C.A.R., M.M., M.F., S.M.C., and F.T.; visualization, S.M.C. and F.T.; supervision, J.M.S. and A.T.L.; project administration, J.M.S.; funding acquisition, J.M.S., A.T.L., S.M.C., M.R.G., and F.T. All authors have read and agreed to the published version of the manuscript. 
Funding: This study was supported by the Dutch Kidney Foundation, grant number $15 \mathrm{O} 141$ (ATL) and 17OKK54 (SMC), ZonMw, grant number 40-000703-97-12463 (ATL) and 114024055 (FT/ATL), and the National Institutes of Health, grant number R01HL134711 (JMS) and R01HL137673 (MRG).

Acknowledgments: We thank Joshua Jefferson and Marian L.C. Bulthuis for their technical support with histology.

Conflicts of Interest: The authors declare no conflict of interest. The funders had no role in the design of the study; in the collection, analyses, or interpretation of data; in the writing of the manuscript, or in the decision to publish the results.

\section{Appendix A}

Supplementary figures.

A

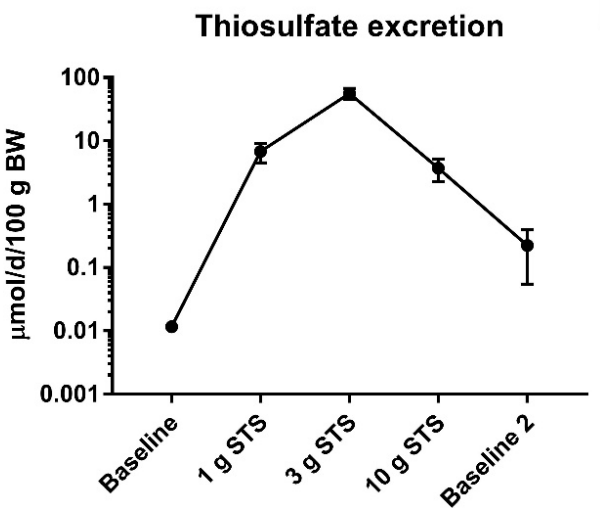

B

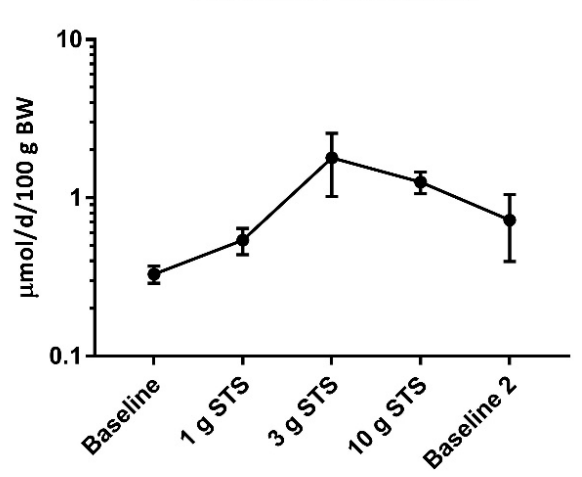

Figure A1. Mean urinary thiosulfate excretion per dose. In a pilot study, sodium thiosulfate (STS) was orally administered via the drinking water at incremental doses to four healthy female Sprague Dawley rats. Highest urinary excretions of (A) thiosulfate and (B) free thiol were reached at a dose of $3 \mathrm{~g} / \mathrm{kg} /$ day STS. BW, body weight. Means \pm SEM.

CON

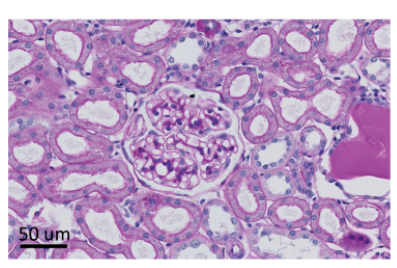

Placenta

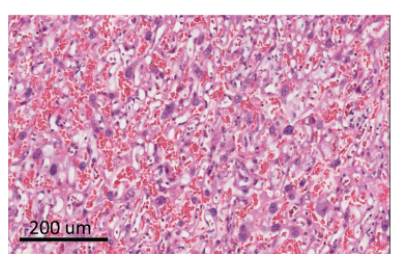

STS (2g)
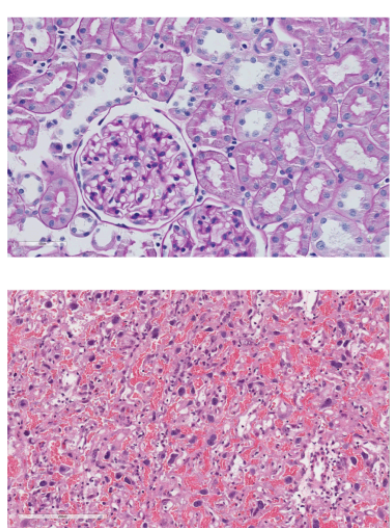

STS (3g)
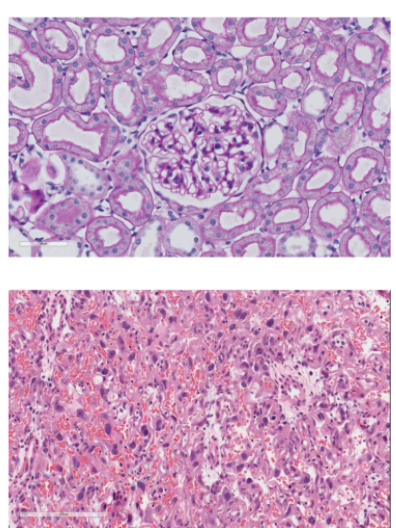

Figure A2. Representative example of glomeruli in PAS staining and labyrinth zone of placentas in HE staining in control and STS treated with $2 \mathrm{~g}$ and $3 \mathrm{~g}$ in Dahl S rat. CON, control; Dahl S, Dahl Salt-Sensitive rat; STS, Sodium Thiosulfate; $2 \mathrm{~g}$, 2 g per kg body weight per day; $3 \mathrm{~g}$, $3 \mathrm{~g}$ per kg body weight per day.

\section{References}

1. Khan, K.S.; Wojdyla, D.; Say, L.; Gülmezoglu, A.M.; Look, P.F.A. Van WHO analysis of causes of maternal death: A systematic review. Lancet 2006, 367, 1066-1074. [CrossRef]

2. Chaiworapongsa, T.; Chaemsaithong, P.; Yeo, L.; Romero, R. Pre-eclampsia part 1: Current understanding of its pathophysiology. Nat. Rev. Nephrol. 2014, 10, 466-480. [CrossRef] [PubMed] 
3. Brown, M.A.; Magee, L.A.; Kenny, L.C.; Karumanchi, S.A.; Mccarthy, F.P.; Saito, S.; Hall, D.R.; Warren, C.E.; Adoyi, G.; Ishaku, S. Hypertensive Disorders of Pregnancy: ISSHP Classification, Diagnosis, and Management Recommendations for International Practice. Hypertension 2018, 72, 24-43. [CrossRef] [PubMed]

4. Mcdonald, S.D.; Han, Z.; Walsh, M.W.; Gerstein, H.C.; Devereaux, P.J. Kidney Disease After Preeclampsia: A Systematic Review. Am. J. Kidney Dis. 2010, 55, 1026-1039. [CrossRef] [PubMed]

5. Sibai, B.; Dekker, G.; Kupferminc, M.; Way, A.S. Pre-eclampsia. Lancet 2005, 365, 785-799. [CrossRef]

6. Dasinger, J.; Davis, G.; Newsome, A.; Alexander, B. The Developmental Programming of Hypertension: Physiological Mechanisms. Hypertension 2016, 68, 826-831. [CrossRef]

7. Karumanchi, S. Angiogenic factors in pre-eclampsia: Implications for clinical practice. BJOG 2018, 125, 1396. [CrossRef]

8. Wang, K.Q.; Ahmad, S.; Cai, M.; Rennie, J.; Fujisawa, T.; Crispi, F.; Baily, J.; Miller, M.R.; Cudmore, M.; Hadoke, P.W.F.; et al. Dysregulation of Hydrogen Sulfide Producing Enzyme Cystathionine gamma-lyase Contributes to Maternal Hypertension and Placental Abnormalities in Preeclampsia. Circulation 2013, 127, 2514-2522. [CrossRef]

9. Holwerda, K.M.; Karumanchi, S.A.; Lely, A.T. Hydrogen sulfide: Role in vascular physiology and pathology. Curr. Opin. Nephrol. Hypertens. 2015, 24, 170-176. [CrossRef]

10. Cindrova-Davies, T.; Herrera, E.A.; Niu, Y.; Kingdom, J.; Giussani, D.A.; Burton, G.J. Reduced cystathionine gamma-lyase and increased miR-21 expression are associated with increased vascular resistance in growth-restricted pregnancies: Hydrogen sulfide as a placental vasodilator. Am. J. Pathol. 2013, 182, 1448-1458. [CrossRef]

11. Holwerda, K.M.; Bos, E.M.; Rajakumar, A.; Ris-stalpers, C.; Van Pampus, M.G.; Timmer, A.; Erwich, J.J.H.M.; Faas, M.M.; Van Goor, H.; Lely, A.T. Hydrogen sulfide producing enzymes in pregnancy and preeclampsia. Placenta 2012, 33, 518-521. [CrossRef] [PubMed]

12. Hu, T.; Guo, X.; Wang, G.; Gao, L.; He, P.; Xia, Y.; Gu, H.; Ni, X.; Ph, D. MiR133b is involved in endogenous hydrogen sulfide suppression of sFlt-1 production in human placenta. Placenta 2017, 52, 33-40. [CrossRef] [PubMed]

13. Chen, D.; Feng, L.; Hodges, J.K.; Lechuga, T.J.; Zhang, H. Human trophoblast-derived hydrogen sulfide stimulates placental artery endothelial cell angiogenesis. Biol. Rep. 2017, 97, 478-489. [CrossRef] [PubMed]

14. Kashfi, K.; Olson, K.R. Biology and therapeutic potential of hydrogen sulfide and hydrogen sulfide-releasing chimeras. Biochem. Pharmacol. 2013, 85, 689-703. [CrossRef]

15. Possomato-Vieira, J.S.; Goncalves-Rizzi, V.H.; Graca, T.U.S.; Nascimento, R.A.; Dias-Junior, C.A. Sodium hydrosulfide prevents hypertension and increases in vascular endothelial growth factor and soluble fms-like tyrosine kinase-1 in hypertensive pregnant rats. Naunyn. Schmiedebergs. Arch. Pharmacol. 2016, 389, 1325-1332. [CrossRef]

16. Snijder, P.M.; Frenay, A.R.; De Boer, R.A.; Pasch, A.; Hillebrands, J.L.; Leuvenink, H.; Van Goor, H. Exogenous administration of thiosulfate, a donor of hydrogen sulfide, attenuates angiotensin II-induced hypertensive heart disease. Br. J. Pharmacol. 2015, 172, 1494-1504. [CrossRef]

17. Koj, A.; Frendo, J.; Janik, Z. Thiosulphate Oxidation by Rat Liver Mitochondria in the Presence of Glutathione. Biochem. J. 1967, 103, 791-795. [CrossRef]

18. Zicha, J.; Dobešová, Z.; Vokurková, M.; Rauchová, H.; Hojná, S.; Kadlecová, M.; Behuliak, M.; Vaněčková, I.; Kuneš, J. Age-Dependent Salt Hypertension in Dahl Rats: Fifty Years of Research. Physiol. Res. 2012, 61, S35-S87.

19. Rapp, J.P.; Garrett, M.R. Will the Real Dahl S Rat Please Stand Up? Am. J. Physiol. Physiol. 2019. [CrossRef]

20. Gillis, E.E.; Williams, J.M.; Garrett, M.R.; Mooney, J.N.; Sasser, J.M. The Dahl salt-sensitive rat is a spontaneous model of superimposed preeclampsia. Am. J. Physiol. Regul. Integr. Comp. Physiol. 2015, 309, 62-70. [CrossRef]

21. Sasser, J.M.; Moningka, N.C.; Cunningham, M.W.; Croker, B.; Baylis, C. Asymmetric dimethylarginine in angiotensin II-induced hypertension. Am. J. Physiol. Regul. Integr. Comp. Physiol. 2010, 298, 740-746. [CrossRef] [PubMed]

22. Van Goor, H.; Fidler, V.; Weening, J.; Grond, J. Determinants of focal and segmental glomerulosclerosis in the rat after renal ablation. Evidence for involvement of macrophages and lipids. Lab Investig. 1991, 64, 754-765. [PubMed] 
23. Charest, P.L.; Vrolyk, V.; Herst, P.; Lessard, M.; Sloboda, D.M.; Dalvai, M.; Haruna, J.; Bailey, J.L.; Benoit-Biancamano, M.O. Histomorphologic Analysis of the Late-term Rat Fetus and Placenta. Toxicol. Pathol. 2018, 46, 158-168. [CrossRef] [PubMed]

24. Sasser, J.M.; Baylis, C. Effects of sildenafil on maternal hemodynamics and fetal growth in normal rat pregnancy. Am. J. Physiol. Regul. Integr. Comp. Physiol. 2010, 298, 433-438. [CrossRef]

25. Zhong, G.; Chen, F.; Cheng, Y.; Tang, C.; Du, J. The role of hydrogen sulfide generation in the pathogenesis of hypertension in rats induced by inhibition of nitric oxide synthase. J. Hypertens. 2013, 21, 1879-1885. [CrossRef]

26. Roy, A.; Khan, A.H.; Islam, M.T.; Prieto, M.C.; Majid, D.S.A. Interdependency of Cystathione $\gamma$-Lyase and Cystathione $\beta$-Synthase in Hydrogen Sulfide-Induced Blood Pressure Regulation in Rats. Am. J. Hypertens. 2012, 25, 74-81w. [CrossRef]

27. Roes, M.E.; Raijmakers, M.T.; De Boo, T.M.; Zusterzeel, P.L.; Merkus, H.M.; Peters, W.H.; Steegers, E.A. Oral $\mathrm{N}$-acetylcysteine administration does not stabilise the process of established severe preeclampsia. Eur. J. Obs. Gynecol. Reprod. Biol. 2006, 127, 61-67. [CrossRef]

28. Shirozu, K.; Tokuda, K.; Marutan, E.; Lefer, D.; Wang, R.; Ichinose, F. Cystathionine $\gamma$-lyase deficiency protects mice from galactosamine/lipopolysaccharide-induced acute liver failure. Antioxid. Redox Signal. 2014, 20, 204-216. [CrossRef]

29. Tokuda, K.; Kida, K.; Marutani, E.; Crimi, E.; Bougaki, M.; Khatri, A.; Kimura, H.; Ichinose, F. Inhaled Hydrogen Sulfide Prevents Endotoxin-Induced Systemic Inflammation and Improves Survival by Altering Sulfide Metabolism in Mice. Antioxid. Redox Signal. 2012, 17, 11-21. [CrossRef]

30. Gillis, E.E.; Mooney, J.N.; Garrett, M.R.; Granger, J.P.; Sasser, J.M. Sildenafil Treatment Ameliorates the Maternal Syndrome of Preeclampsia and Rescues Fetal Growth in the Dahl Salt-Sensitive Rat. Hypertension 2016, 67, 647-653. [CrossRef]

31. Barton, J.R.; Sibai, B.M. Controversies Regarding Diagnosis and Treatment of Severe Hypertension in Pregnancy. Clin. Obstet. Gynecol. 2017, 60, 198-205. [CrossRef] [PubMed]

32. Giannubilo, S.R.; Bezzeccheri, V.; Cecchi, S.; Landi, B.; Battistoni, G.I.; Vitali, P.; Cecchi, L.; Tranquilli, A.L. Nifedipine versus labetalol in the treatment of hypertensive disorders of pregnancy. Arch. Gynecol. Obstet. 2012, 286, 637-642. [CrossRef] [PubMed]

33. Donhoffer, S.; Svezgvari, G.; Jarai, I.; Farkas, M. Thiosulphate Metabolism in the Animal Organism. Nature 1959, 184, 994-995.

34. Olson, K.R.; DeLeon, E.R.; Gao, Y.; Hurley, K.; Sadauskas, V.; Batz, C.; Stoy, G.F. Thiosulfate: A readily accessible source of hydrogen sulfide in oxygen sensing. Am. J. Physiol. Regul. Integr. Comp. Physiol. 2013, 305, 592-603. [CrossRef] [PubMed]

(C) 2020 by the authors. Licensee MDPI, Basel, Switzerland. This article is an open access article distributed under the terms and conditions of the Creative Commons Attribution (CC BY) license (http://creativecommons.org/licenses/by/4.0/). 